\title{
Transient tyrosinemia of the newborn
}

INSERM

\section{Source}

INSERM. (1999). Orphanet: an online rare disease and orphan drug data base. Transient tyrosinemia of the newborn. ORPHA:3402

Transient tyrosinemia of the newborn is a benign disorder of tyrosine metabolism detected upon newborn screening and often observed in premature infants. It shows no clinical symptoms. It is characterized by tyrosinemia, moderate hyperphenylalaninemia, and tyrosiluria that usually resolve after 2 months of age. 